\title{
The Uniformity Tests of A Rainfall Generator
}

\author{
Bo LIU ${ }^{1, a}$, Xiaolei WANG ${ }^{1, b^{*}}$, Teng SU ${ }^{2, c}$ and Zhaojing KANG ${ }^{1, d}$ \\ ${ }^{1}$ College of Meteorology and Oceanography, PLA University of Science and Technology, China \\ 2 Jiuquan Satellite Launch Center, China \\ a liubonanjing@163.com, b wangxiaolei0199@sina.com, ' njsuteng5050@163.com \\ , d'kangzhaojingnj@163.com
}

Keywords: Rainfall Generator, Uniformity, Test.

Abstract. A practical rainfall generator for meteorological metrology research has been designed. The rainfall generator is adopted to produce a rainfall environment for rainfall instruments test and calibration. The uniformity of the rainfall generator is tested with rainfall collectors and the Christiansen coefficient of Uniformity (CUC) ranged from $80.57 \%$ to $87.32 \%$. The results obtained by the rainfall generator indicate that the middle part of the whole test plot is consistent and raingauges can be planted in the four quarters of the compass so as to carry out rainfall intensity test.

\section{Introduction}

Measurements of rainfall have been widely applied in meteorology, hydrology, agricultural, and soil sciences[1,2]. Many types of rain gauges and measurement techniques are developed and in operational use. All types of rain gauges can be divided into catching and non-catching instruments. At present, there is no generally agreed test equipment for the performance assessment of any type of rain gauges. The performance assessment of these instruments, especially the non-catching ones, mainly depends on the field intercomparisons, which are costly and time-consuming[3].

An alternative method to assess both catching and non-catching rain gauges is to generate artificial rainfall which is similar to the natural rainfall and can be controlled. Many researches on rainfall simulation have been done since 1920s. Many kinds of rainfall simulators are developed and successfully used in soil erosion studies[4,5,6]. Some works have been published analyzing the characteristics of the artificial rainfall[7,8,9]. The following requirements are essential for rainfall simulators to be applied to the performance assessment of rain gauges: (1) the similar parameters such as drop size distribution, drop terminal velocity between the artificial and natural rainfall, (2) the time stability of artificial rainfall during one experiment, (3) homogeneous spatial rainfall distribution.

Based on these requirements, a new rainfall generator was developed. The present study aims to test and assess the uniformity of the artificial rainfall generated by the rainfall generator.

\section{Material and Methods}

Rainfall generator The rainfall generator is a single nozzle type rainfall simulator. The main components of the rainfall generator are a nozzle, a pedestal, a water feeding system, a control box and a windshield surrounding the pedestal (Fig.1). The rainfall intensity ranges from $6.5 \mathrm{~mm} / \mathrm{h}$ to $60 \mathrm{~mm} / \mathrm{h}$ by adjusting the pressure to the nozzle inlet and changing different nozzles. The effective rainfall area is $2.0 \mathrm{~m} \times 2.0 \mathrm{~m}$. 


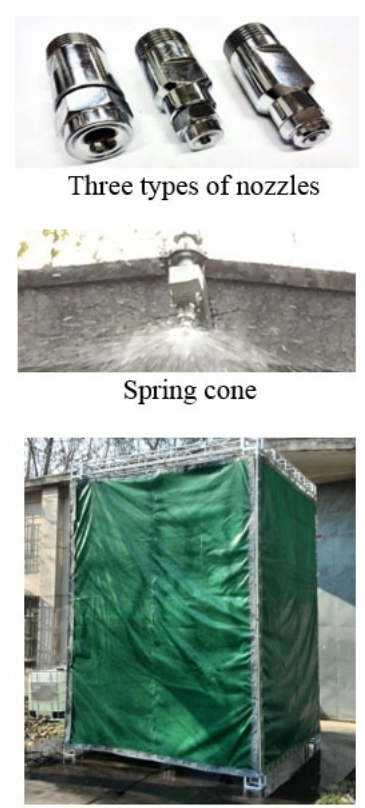

Windshield surrounding

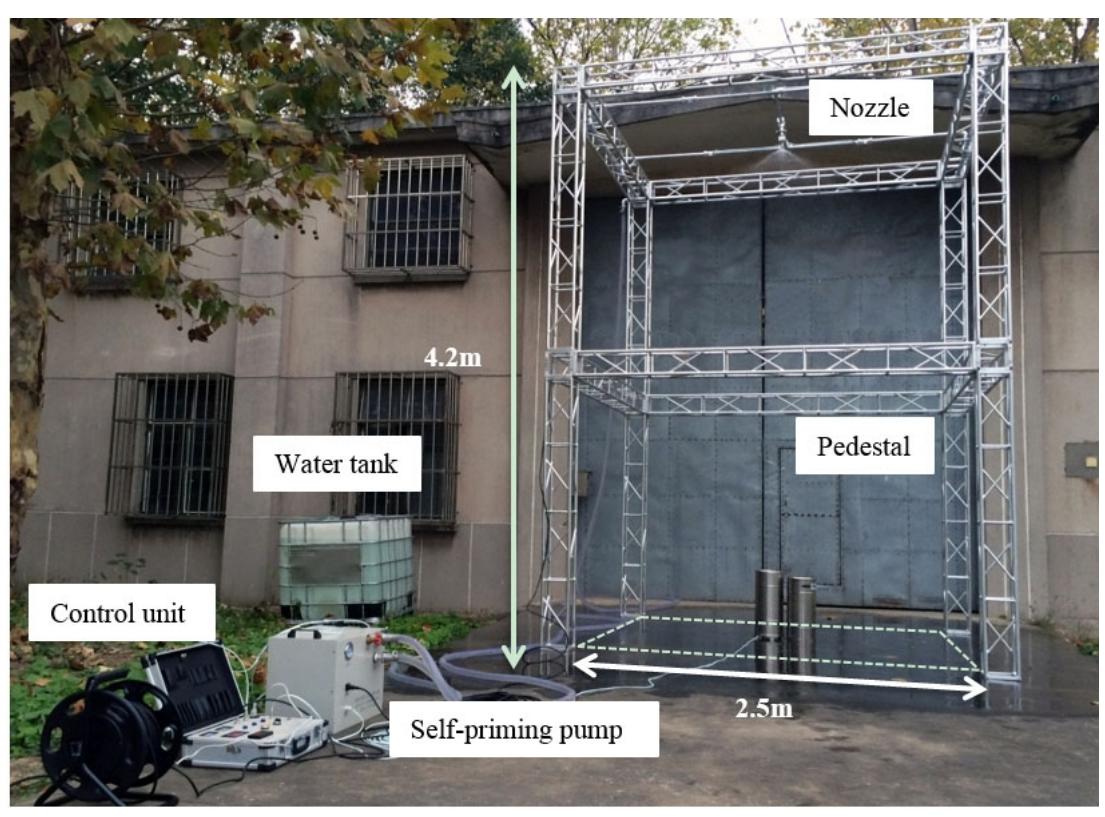

Main components of the rainfall generator

Fig. 1. The rainfall generator for meteorological metrology research

The nozzle is the key part of the rainfall generator which should be capable of wetting a preferably large area and producing water distribution drops with a drop size distribution similar to that of natural rainfall. After evaluating different types of nozzles, the full-cone jetting nozzles were selected. Three types of nozzles were used to generate different rainfall intensities (Table 1).

Table 1 Specifications of the selected nozzles.

\begin{tabular}{cccc}
\hline Type & Pressure [bar] & Intensity $[\mathrm{mm} / \mathrm{h}]$ & $\mathrm{D}_{50}[\mathrm{~mm}]$ \\
\hline A & 0.85 & 8 & 0.68 \\
B & 0.60 & 18 & 0.92 \\
C & 0.25 & 40 & 1.97 \\
\hline
\end{tabular}

An aluminum alloy pedestal was built in order to hold the nozzle $4.2 \mathrm{~m}$ above the ground. A self-priming pump, with a power consumption of $1.2 \mathrm{KW}$, drew water from a $1 \mathrm{~m}^{3}$ water tank to the nozzle inlet. In order to control the beginning and ending of the simulated rainfall, a solenoid valve was inserted in the pipe just before the nozzle. The solenoid valve opened when it was energized by a $12 \mathrm{~V}$ electric-current, operated by the control box. The response speed of the solenoid valve is fast, preventing the nozzle from dripping after the valve is shut.

Uniformity Test Methods In order to quantitatively assess the homogeneous and reproducibility of the artificial rainfall, 121 circular rainfall collectors with diameter of $8.5 \mathrm{~cm}$ and height of $8 \mathrm{~cm}$ were distributed on the whole test plot (Fig 2). For each type of nozzle, two separate test runs were undertaken. During each test, the exposure time of the rainfall collectors to the artificial rain was 10 min. The individual collectors were weighted by a precision electronic balance, yielding the rainfall amount at each position. The rainfall intensity values were calculated, as shown in Eq.1 and spatially interpolated by Kriging method to get the contour map.

$$
I=600 \frac{m}{\rho \cdot s \cdot t}
$$


where, $I$ is the rainfall intensity $([\mathrm{mm} / \mathrm{h}]), m$ is the weight of water in the rainfall collector $([\mathrm{g}]), S$ is the gauge mouth area $\left(\left[\mathrm{cm}^{2}\right]\right), t$ is the experiment duration of 10 minutes, $\rho$ is density of water([g/ $\left.\left.\mathrm{cm}^{3}\right]\right)$.

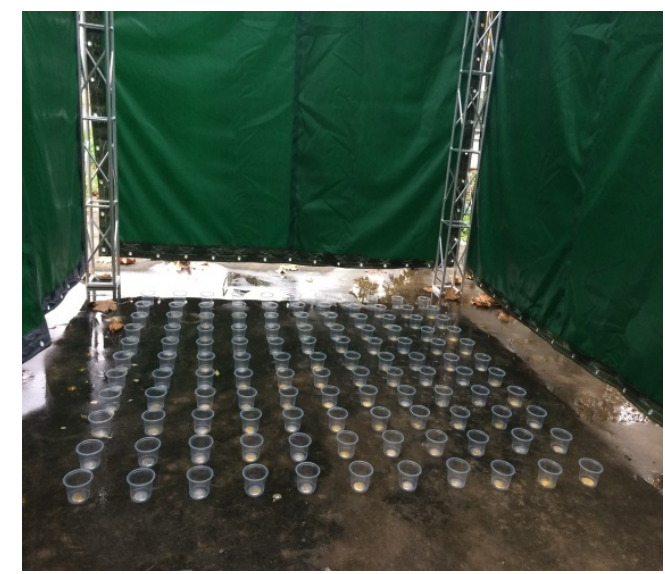

( a ) Graphic of test zone

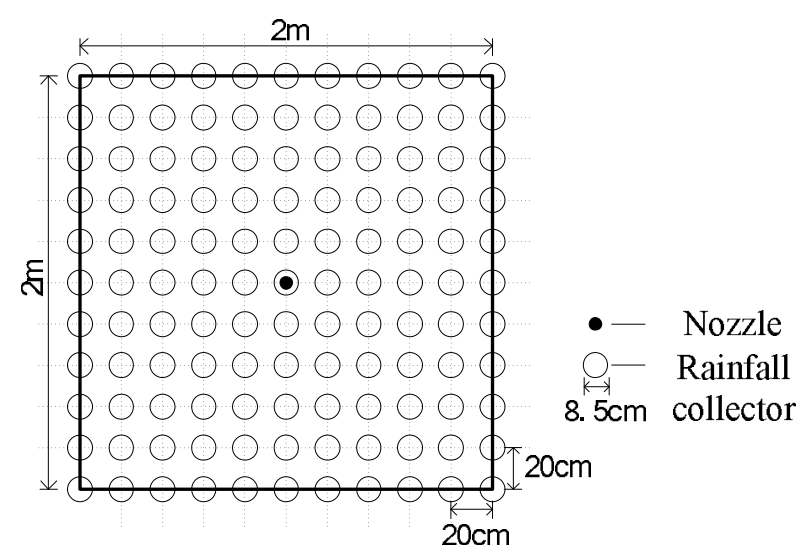

( b ) Graphic of distribution of rainfall collectors

Fig. 2. The test method of rainfall generator

The rainfall intensity values were calculated and spatially interpolated by Kriging method to get the contour map. The most widely used coefficient of uniformity defined by Christiansen[10] was calculated, as shown in Eq.2 . The deviation between the two repetitions was calculated and normalized with the mean rainfall intensity value at each position to express the reproducibility of the rainfall.

$$
C U C=\left(1-\frac{\sum_{i=1}^{n}\left|I_{i}-\bar{I}\right|}{n \bar{I}}\right) \times 100 \%
$$

where, $I_{i}$ is rainfall amount at location i, $\bar{I}$ is average amount of rainfall and $n$ is the number of rainfall collectors.

\section{Results and Discussion}

CUC of rainfall generator The Christiansen coefficient of Uniformity (CUC) is shown in Table 2. The CUC increases with the ascending nozzle diameter of type A, type B and type $\mathrm{C}$. It can be seen from Table 2 that the results of both nozzle type $\mathrm{A}$ and type $\mathrm{B}$ are consistent, while results of type $\mathrm{C}$ showed a variance. Overall, the test results of CUC are all larger than $80 \%$, which agreed with Moazed[11].

Table 2 Test results of CUC.

\begin{tabular}{ccc}
\hline Type & The first test & The second test \\
\hline A & $80.57 \%$ & $80.12 \%$ \\
B & $82.67 \%$ & $82.58 \%$ \\
C & $84.51 \%$ & $87.32 \%$ \\
\hline
\end{tabular}

Spatial rainfall distribution The spatial distribution of three nozzles for all fields for the first time are shown in Figure 3. The patterns of distribution are very similar. The rainfall intensity suface maps have a shape of mountain that the highest rainfall intensity is the area under nozzle and it decreases from 
center to remote locations, excluding the corners. The corners failed to follow the trend because the raindrops firstly sprayed to the windshied surrounding are splashed into the corners. The rainfall intensity contour maps have a shape of some closed circles in the middle areas but have irregular shapes near the corners.

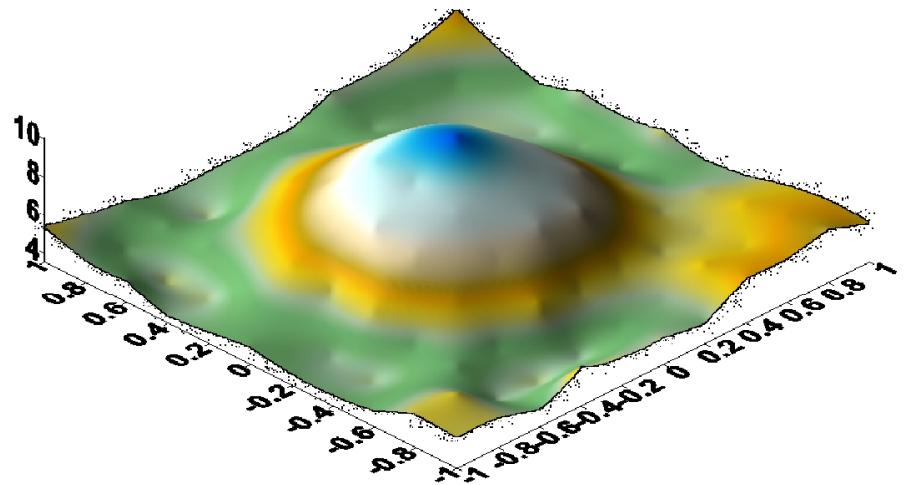

( a ) Surface map of nozzle type A

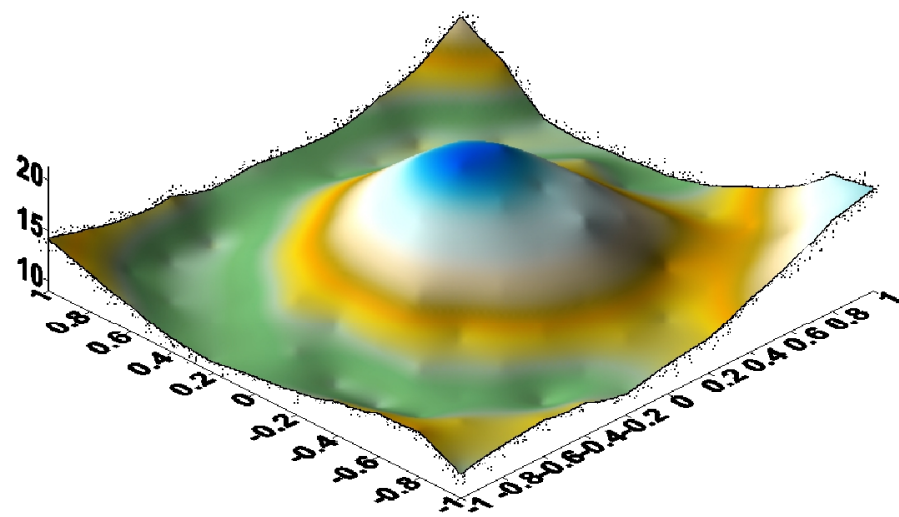

( c ) Surface map of nozzle type B

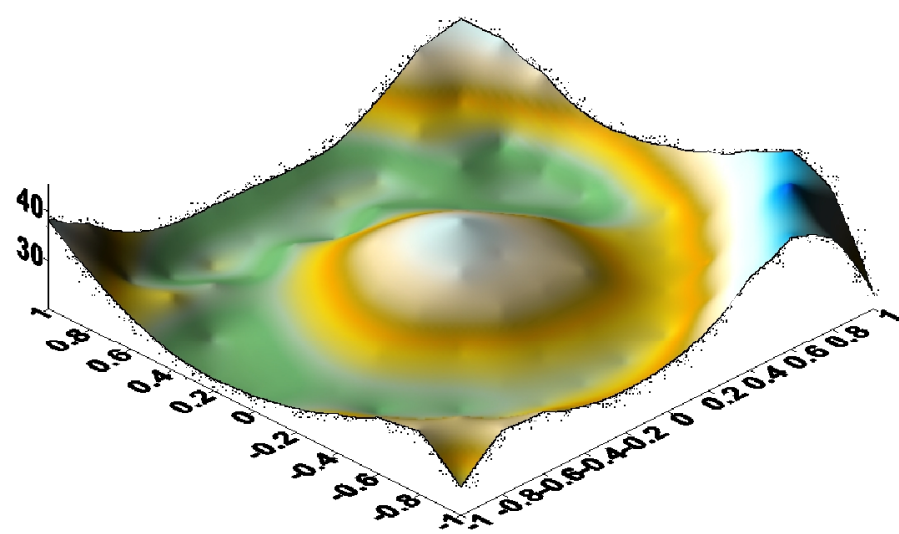

(e ) Surface map of nozzle type C

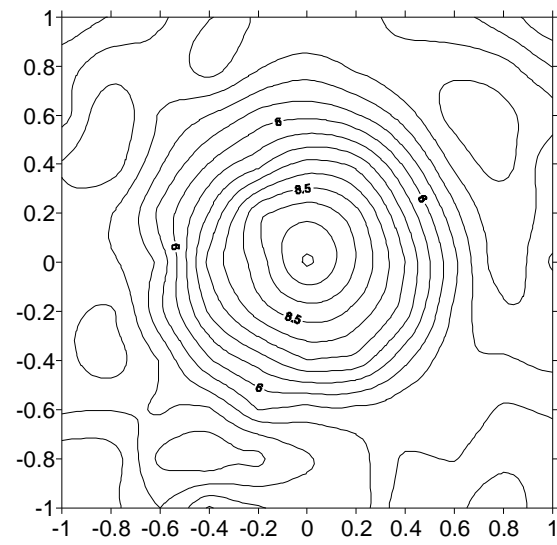

( b ) Contour map of nozzle type A

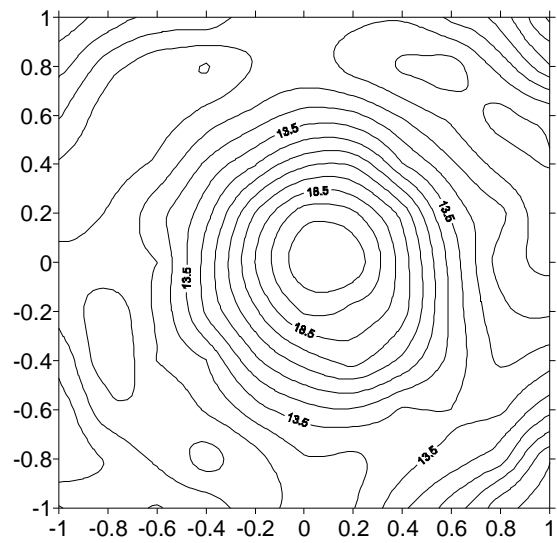

( d ) Contour map of nozzle type B

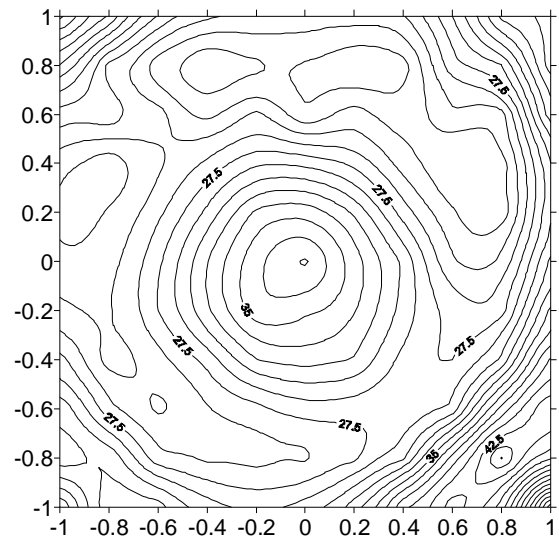

( f ) Contour map of nozzle type C

Fig. 3. The rainfall intensity spatial distribution plots of the first test

\section{Conclusions}

A rainfall generator presented CUC of three type nozzle ranged from $80.57 \%$ to $87.32 \%$, which all lager than $80 \%$, similar results were considered adequate for successful rainfall simulator for soil and water conservation. The surface map and contour map showed, that although CUC of the whole test plot is not able to provide a very close resemblance of natural rainfall, but the rainfall intensity around 
the circle plot are consistent. The test results indicate that raingauges can be located in the four quarters of the compass so as to carry out rainfall intensity test.

For further understanding of the rainfall generator, more micro characteristics like diameter and velocity of artificial rainfall drops should be studied and a method of increasing the CUC should be approched. As these characteristics are improved and are respectively similar to the natural rainfall, the developed rainfall generator can be used in test and measurement research to reproduce rainfall environment for the test of rainfall instruments.

\section{References}

[1] A. A. Azbukin, V. V. Kalchikhin, A. A. Kobzev, V. A. Korolkov, and A. A. Tikhomirov, Determination of calibration parameters of an optoelectronic precipitation gage, Atmospheric and Oceanic Optics 27.5 (2014) 432-437.

[2] M. Colli, L. Lanza, P. L. Barbera, Metrological requirements for a laboratory rainfall simulator , Geophysical Research Abstracts Vol. 17(2015), EGU2015-12084.

[3] K. Wong, Performance of Several Present Weather Sensors as Precipitation Gauges, WMO TECO, (2012) 16-18.

[4] T. Iserloh, J. B. Ries, J. Arnáez, C. Boix-Fayos, V. Butzen, A. Cerdà, ... and S. Wirtz, European small portable rainfall simulators: a comparison of rainfall characteristics, Catena 110 (2013) 100-112.

[5] D. Dunkerley, Rain event properties in nature and in rainfall simulation experiments: a comparative review with recommendations for increasingly systematic study and reporting, Hydrological Processes 22.22 (2008) 4415-4435.

[6] T. Iserloh, W. Fister, M. Seeger, H. Willger and J. B. Ries, A small portable rainfall simulator for reproducible experiments on soil erosion, Soil and Tillage Research, 124, (2012) 131-137.

[7] G.Kathiravelu, T. Lucke, R. White, and P. Nichols, Review on design requirements of a rainfall simulator for urban stormwater studies, In Proceedings of the 2014 Stormwater Queensland Conference, (2014) 1-13.

[8] S. S. Júnior and E. Q. Siqueira, Development and Calibration of a Rainfall Simulator for Urban Hydrology Research. In 12th International Conference on Urban Drainage, Porto Alegre/Brazil. (2011) 1-8.

[9] T. G. Wilson, C. Cortis, N. Montaldo and J. D. Albertson, Development and testing of a large, transportable rainfall simulator for plot-scale runoff and parameter estimation, Hydrology and Earth System Sciences, 18(10), (2014) 4169-4183.

[10] J. E. Christensen, Irrigation by sprinkler. California Agricultural Experimental Station, Berkeley, Res. Bull. 670, (1942) 123.

[11] H. Moazed, A. Bavi, S. Boroomand-Nasab, A. Naseri and M. Albaji, Water Uniformity Coefficient in Solid Set Systems, Journal of applied sciences, 10(16), (2010) 1792-1796. 